\title{
Исследования социальной ответственности компании
}

\author{
Нагорнов A.B. ${ }^{22}$, Солнцева М.C. ${ }^{23}$
}

Данный обзор посвящен корпоративной сочиальной ответственности как составному элементу концепции устойчивого развития бизнеса. В то время как в развитых странах дискуссии о корпоративной сочиальной ответственности, стартовавшие от обсуждения проблематики роли бизнеса в поддержании окружающей среды, начали появляться уже в 1970-х годах, российские компании стали уделять внимание корпоративной социальной ответственности в том виде, в котором ее воспринимают в развитом мире, относительно недавно. Представляемый нами обзор направлен на ознакомление с основными вопросами корпоративной социальной ответственности. Для реализации поставленной цели нами рассматриваются зарубежные дискуссионные статьи и исследования, а также публикачии российских авторов по следующим вопросам:

- концепция устойчивого развития;

- корпоративное гражданство;

- взаимодействие корпораиий с заинтересованными лицами;

- сочиильно ответственные инвестиции;

- корпоративная сочиильная отчетность.

\section{1. Основные направления дискуссий концепции устойчивого развития бизнеса}

\section{1. Критерии устойчивости развития бизнеса}

В настоящее время в финансовой литературе под «устойчивым развитием бизнеса», как правило, понимают такой вид добровольного ведения бизнеса, который удовлетворяет не только экономическим критериям, но и экологическим и социальным интересам общества и государства. Нередко термин «устойчивое развитие» бизнеса воспринимается абсолютным синонимом корпоративной социальной ответственности (КСО) (например, Финч [Finch, 2005]).

Критерии устойчивого развития бизнеса, однако, менялись по мере преобразования идеи устойчивого развития общества в целом, в силу чего единого определения до сих пор не существует. Если у истока развития проблематики появились разговоры о необходимости ведения бизнеса с учетом заботы об окружающей среде, то уже довольно скоро подключился социальный аспект, являющийся в настоящее время неотьемлемой частью устойчивого развития. Однако в последних работах можно найти мнение о необходимости включения и морального элемента в ряд критериев устойчивого развития бизнеса (Бекманн и Пайс [Beckmann, Pies, 2007]). С другой стороны, Басен [Bassen, Meyer, 2006], акцентируя внимание на динамичном характере концепции, утверждает, что ввиду постоянного изменения концепции корпоративной ответственности ее содержание во многом зависит от теоретических парадигм, локальных экономических традиций, специфики ведения бизнеса и исследуемого периода времени. Соответственно единого определения не только нет, но и не может быть.

\footnotetext{
${ }^{22}$ Магистр 2-го курса программы «Стратегическое управление финансами фирмы» ГУ-ВШЭ.

${ }^{23}$ Магистр 2-го курса программы «Стратегическое управление финансами фирмы» ГУ-ВШЭ, стажер-исследователь Лаборатории корпоративных финансов.
} 
Отсутствие единой терминологии представляет собой одну из наиболее существенных проблем корпоративной социальной ответственности. Обсуждению терминологии посвящено множество работ, а авторскими определениями начинается любое исследование. Не имея четкого представления о понятии КСО, компании по-разному интерпретируют как составляющие компоненты корпоративной социальной ответственности, так и явление устойчивого развития бизнеса. По-разному понимается терминология и остальными участниками общества, о чем свидетельствуют опросы населения, менеджеров, государственных деятелей, проведенные Ассоциацией менеджеров в России [Ассоциация менеджеров, 2003; Ассоциация менеджеров, 2004]. Данная проблема свойственна не только России, о чем говорит, например, работа Беббингтон и Грей [Bebbington, Gray, 2001], посвященная тщательному анализу различий в понимании концепции устойчивого развития. Авторы проводят сравнительный анализ терминологии в мировой литературе, в опубликованных стратегиях и экологических отчетах компаний Великобритании. В статье также проведен анализ того, насколько ключевой для бизнеса является концепция устойчивого развития, основанный на разработанной системе из 16 категорий - степеней раскрытия информации.

Сама идея устойчивого развития бизнеса появилась как одна из составляющих, более того - как необходимое условие устойчивого развития общества в целом. Ряд исследований макроэкономического характера посредством отражения влияния устойчивого (или, напротив, неустойчивого) развития бизнеса на такие характеристики, как общее загрязнение окружающей среды, национальный экономический рост и прочие экологические и макроэкономические факторы показали необходимость развития КСО. Так, в работе Бертинелли, Стробл [Bertinelli, Strobl, 2006], сначала на теоретической модели, а затем эмпирически (на данных развитых и развивающихся стран) показывается, что уровень загрязнения окружающей среды зависит от того, насколько развиты в стране инвестиции в новые технологии, сберегающие окружающую среду. Таким образом, от степени развитости социальноответственных инвестиций в стране будет зависеть снижение общего уровня загрязнения, его стабилизация на определенной границе или же, напротив, рост.

Здесь же следует обратить внимание на работу Кумари [Kumari, 2007], рассматривающую взаимосвязи устойчивого развития и бедности, технологического и экономического прогресса, сельского хозяйства, управления водными ресурсами, а также пытающуюся разобраться в определении термина «устойчивого развития». Проведенный анализ, базирующийся в основном на авторских рассуждениях, позволил выявить недостатки в политике распространения и введения в действие концепции устойчивого развития. Одним из главных выводов является заключение о необходимости совместных усилий бизнеса, государства и прочих заинтересованных в устойчивом развитии общественных институтов.

\section{2. Основные теоретические идеи и работы}

Практически все работы, посвященные устойчивому развитию бизнеса, можно систематизировать в соответствии с образовавшимися с момента появления концепции подходами к корпоративной социальной ответственности. Приведенная ниже классификация, представленная в работе Финча [Finch, 2005], посвященной мотивам приверженности компании устойчивому развитию, позволяет рассмотреть наиболее широкий круг исследований.

\section{Устойчивое развитие бизнеса с точки зрения агентской теории}


С точки зрения агентской теории приверженность компанией идее устойчивого развития рождает агентские проблемы. Связано это с тем, что положительные эффекты ведения бизнеса, обращающего внимание на проблемы экологии и общества, сказываются в основном на репутации менеджеров, в то время как осуществление затрат КСО происходит за счет собственников компании и снижает их благосостояние. Соответственно, если рассматривать в качестве основной цели корпорации максимизацию функции полезности ее акционеров, устойчивое развитие бизнеса становится излишней и вредящей осуществлению этой цели концепцией. Данный взгляд был тщательно исследован Фридманом, считавшим, что участие бизнеса в благотворительных мероприятиях представляет собой нерациональное использование капитала корпорации [Friedman, 1962, 1970].

Так как рассмотрение устойчивого развития бизнеса с данной точки зрения представляет собой существенные издержки для компании, то возникает вопрос стимулирования компаний. Церин, Карлсон [Cerin, Karlson, 2002] утверждают, что возможно стимулировать устойчивое развитие бизнеса, если рассмотреть данную проблему с точки зрения прав собственности. Так как чаще всего экологические последствия производства представляют собой внешние эффекты, то авторы предлагают ввести торговлю правами на выбросы в соответствии с жизненным циклом продукции. При введении торговли правами на загрязнения приобретение таких прав переходит в разряд таких же затрат на производство продукции, как и использование ресурсов, что, по мнению авторов, должно стимулировать компании к более социально ответственному поведению и развитию инноваций для более экологически чистого производства. Работа, однако, относится к классу теоретических (основанных на теории трансакционных издержек и теории прав собственности) и проверена лишь на гипотетическом численном примере.

\section{Устойчивое развитие бизнеса с точки зрения корпоративной социальной эффективности ${ }^{24}$}

Если агентский подход говорит о том, что компании могут испытывать устойчивый рост только за счет финансовых потерь, то подход с точки зрения эффективности корпоративной социальной деятельности показывает, что это далеко не всегда так. Напротив, ряд исследований демонстрирует, что компании, придерживающиеся критериев устойчивого развития, нередко показывают даже более значимые финансовые результаты.

Изучению взаимосвязи между КСО и результатами деятельности компаний посвящено множество исследований. Единые выводы пока не получены: есть как работы, заключающие, что между этими факторами существует строго положительная зависимость, так и исследования, обнаруживающие исключительно отрицательную зависимость, а также работы, провозглашающие отсутствие подобной зависимости.

Исследования данного раздела можно условно разделить на ряд категорий - в зависимости от метода их проведения: дискуссионные, теоретические, статистические, эконометрические ${ }^{25}$. Большинство публикаций посвящено именно первому типу, что неслучайно. Определить корректно статистическую или эконометрически заверенную зависимость между КСО фирмы и финансовыми

\footnotetext{
${ }^{24}$ Corporate social performance.

25 Обзор, представленный в работе Басена и Майера [Bassen, Meyer, 2006], дает иную классификацию: теоретический, портфельный анализ, метод событий, регрессионный анализ. Исследования могут быть также распределены по принципу влияния на бухгалтерские или рыночные показатели компании.
} 
показателями крайне проблематично. Во-первых, может иметь место явление ложной зависимости; во-вторых, может проявиться проблема эндогенности. „Во многом по этим причинам, а также в связи с определенными сложностями нахождения данных и разработки прокси-переменных большинство публикаций носит качественный характер.

Тем не менее ряд авторов представляют эмпирический анализ с использованием различных эконометрических тестов для элиминирования упомянутых проблем. Так, в работе Бечетти, Джакомо [Becchetti, Giacomo, 2005] проведено исследование воздействия корпоративной социальной ответственности на эффективность деятельности компании на панельных данных американских компаний. При помощи построения GARCH $(1,1)$ моделей авторы проверяют относительный риск инвестиционной стратегии хранения акций, как входящих в социальный индекс Domini, так и на контрольной выборке, используемой для выявления эффекта присутствия в индексе. Бечетти и Джакомо заключают, что КСО приводит к частичному сдвигу целей компании от максимизации благосостояния акционеров к многокритериальной максимизации благосостояния заинтересованных лиц. Что касается эффективности функционирования компании, то авторами было выявлено существенное увеличение показателя продаж на сотрудника при снижении доходности акций. При этом включенные в индекс Domini компании демонстрируют меньшую волатильность доходности и большую устойчивость к различным резким изменениям на рынке. Полученные выводы авторы объясняют такими негативными для компании эффектами КСО, как более высокие затраты на рабочую силу, а также получаемыми от этого положительными эффектами в виде появления у персонала мотивации и чувства включенности в процесс производства, что увеличивает производительность.

Изучению влияния КСО на краткосрочную и долгосрочную доходность акций компаний посвящена и работа Браммера, Брукса и Павелина ([Brammer, Brooks, Pavelin, 2005]). Авторы рассматривают влияние, оказываемое на доходность акций компаний, включенных в рейтинг ста лучших американских социально ответственных компаний (America's 100 Best Corporate Citizens). К моменту проведения исследования данный рейтинг публиковался на ежегодной основе в течение 5 лет. Авторы рассматривают доходность акций компаний, попавших в рейтинг, как в течение 21 дня до и после объявления очередного рейтинга, так и в течение года после его оглашения. Для краткосрочного периода исследователи рассчитывают избыточную доходность (ежедневную и накопленную). Для долгосрочного периода применяется регрессионный анализ с использованием двух методологий рассмотрения влияния характеристик компаний на доходность, одна из которых подразумевает построение линейных регрессий для панельных данных, другая применяет портфельный подход, представляя тем самым анализ временных рядов. Авторы наблюдают небольшую положительную избыточную доходность в течение 21 дня до и после объявления рейтинга. Более затруднена интерпретация результатов анализа долгосрочной доходности. Полученная авторами доходность для компаний, включенных в рейтинг, в среднем на 3\% ниже доходности S\&P 500. Однако со скидкой на проведенное исследование характеристик компаний (в рамках которого была доказана несостоятельность S\&P 500 как планки для сравнения) авторы заключили наличие более высокой доходности для компаний, включенных в индекс, и на более длинных интервалах. Тем не менее вопрос ключевого фактора, приводящего к более высоким котировкам акций социально ответственных компаний (изучение инвесторами рейтинга или же непосредственное влияние корпоративной социальной деятельности на будущие показатели фондового рынка), остается открытым. 


\section{Устойчивое развитие бизнеса с точки зрения использования ресурсов}

Устойчивое развитие бизнеса с точки зрения использования ресурсов заключает, что компании с устойчивым развитием, особенно те, которые уделяют наибольшее внимание экологическим проблемам, могут не только улучшить свои финансовые показатели, но и приобрести серьезные конкурентные преимущества. Измерение влияния воплощения концепции устойчивого развития бизнеса на конкурентное преимущество компании крайне затруднено. Тем не менее в работе Мель [Mele, 2004], отражающей развитие КСО в Испании, на основе анкетирования представителей бизнеса было выявлено, что достижение конкурентных преимуществ рассматривается менеджерами испанских компаний как второе по значимости положительное последствие КСО после улучшения корпоративной репутации. В свою очередь Верзер, Чандлер [Werther, Chandler, 2005] на дискуссионном уровне доказывают, что правильный баланс стратегии компании, управление брендом и КСО приводят к устойчивому конкурентному преимуществу корпорации. Однако для достижения этой цели необходимо эффективное интегрирование принципов устойчивого развития в операционную деятельность организации.

\section{Устойчивое развитие бизнеса с точки зрения стейкхолдеров}

Рассмотрение устойчивого развития бизнеса со стороны спроса и предложения подразумевает наличие некоторого уровня социально ответственных инвестиций, при котором, с одной стороны, максимизируется прибыль компании, а с другой стороны, удовлетворяются желания и ожидания стейкхолдеров. В то время, когда Маквильямс и Сигель [McWilliams, Siegel,2001] утверждают, что существует такой уровень социально-ответственных инвестиций, в работе Макей, Макей, Барни [Mackey, Mackey, Barney,2005] рассматриваются различные ситуации. Авторы начинают с теоретического моделирования и определения состояния равновесия, когда цены акций максимизирующих прибыль компаний и компаний, ведущих социально ответственный бизнес, равны. Получив равновесие, в котором доля социально ответственных инвесторов равна доле социально ответственных компаний, а доля максимизирующих благосостояние инвесторов равна доле традиционно максимизирующих прибыль компаний, авторы рассматривают ситуации, когда данное соотношение не выполняется (спрос на КСО выше предложения, либо предложение КСО выше спроса), а также рассматривают, как при этом меняется стоимость компании. Проведенный анализ позволил заключить, что в некоторых случаях социально ответственная деятельность компании не максимизирует приведенную стоимость будущих денежных потоков компании, однако при этом максимизирует ее рыночную стоимость. Однако возможны ситуации неблагоприятного для компании соотношения спроса и предложения на КСО, в связи с чем инвестирование в социально ответственные проекты приведет к снижению стоимости компании.

Данное направление в настоящее время представляет собой mainstream и основано на идее тесной взаимосвязи устойчивого развития бизнеса с ожиданиями и требованиями заинтересованных в компании сторон. Работы, представленные в рамках данной концепции, подробно рассмотрены в разделе «3. Взаимодействие корпораций с заинтересованными лицами», ввиду чего не рассматриваются в данном разделе.

\section{2. Исследования проблемы корпоративного гражданства}


Необходимость устойчивого развития бизнеса в настоящий момент не вызывает сомнений. Действительно, о невозможности или вреде для компании устойчивого развития говорили только представители первого из рассмотренных выше направлений (агентский подход), а также часть приверженцев второго взгляда (с точки зрения результативности). Однако если сейчас не возникает вопроса о необходимости устойчивого развития, то проблема более широкого распространения и нахождение институтов, ответственных за распространение идей КСО, до сих пор остается открытой.

Так, согласно проведенному анализу документации, способствующей распространению идеи устойчивого развития в ряде стран, Каратти и Касио [Caratti, Cascio, 2006] показали, что на уровне Европы главенствующую роль играет Европейский Союз. Таким образом, авторы рассматривают формальные способы регулирования устойчивого роста.

Однако есть и другое мнение. Внедрение в практику идей устойчивого развития бизнеса невозможно без морального компонента, утверждают Бекманн, Пайс [Beckmann, Pies, 2004]. Авторы показали, что для достижения долгосрочного устойчивого развития необходимо наличие так называемой «игры с положительной суммой выигрыша», выгодной всем агентам сообщества. Данное условие вовсе не означает, что между обществом, бизнесом, государством и прочими агентами не существует конфликтов интересов. Наличие разногласий неизбежно, однако при сдвиге основного внимания на институциональные организации, направленные на смягчение конфликтов, возможно не только снижение расхождений интересов, но и нахождение и развитие общих целей. Речь идет об организациях, основанных на представлениях общества о морали, но при этом имеющих законную основу. Так как основная роль внедрения в жизнь устойчивого развития принадлежит «глобальному управлению», включающему совместные действия политики, бизнеса и общества, авторы показывают, что корпоративное гражданство способно стать связующим звеном между бизнесом и обществом и стимулировать устойчивое развитие. Роль звена корпоративное гражданство может выполнять за счет морального компонента принятия компаниями «порядковой ответственности» (ordo-responisibility). При этом корпоративное гражданство состоит из двух основных аспектов:

- внутренней порядковой ответственности, отвечающей за внутрифирменные процессы компании (отсюда необходимость развития корпоративного управления);

- внешней порядковой ответственности, представляющей собой ответственность компаний перед обществом, в котором она функционирует. Описанное последствие формирования корпоративного гражданства, оказывающее стимулирующее воздействие на устойчивое развитие, на самом деле не столь однозначно. Едва ли не самым острым вопросом при обсуждении корпоративного гражданства является взаимодействие двух наиболее крупных игроков: корпоративного сектора и мультинациональных компаний. Согласно рассмотренной работе (и данное мнение широко распространено), влияние на общественное развитие взаимоотношений бизнеса и общества посредством создания стратегических планов социально ответственного инвестирования положительно. Однако есть и кардинально противоположное мнение, исходящее из идеи, что корпоративное гражданство представляет собой некое прикрытие, используемое мультинациональными компаниями для максимизации прибыли в более спокойных и безрисковых условиях.

Обширная работа в исследовании данного вопроса была проделана Сиротински [Sirotinsky, 2004]. Автор поставил перед собой задачу рассмотрения значения корпоративного гражданства в условиях снижающейся роли 
государственного регулирования и усиления роли гражданского общества, ставящего перед собой в качестве одной из целей регулирование экологических условий, прав человека и условий труда в мультинациональных компаниях. Возможность влияния корпоративного гражданства на деятельность мультинациональной компании была продемонстрирована автором на примере компании Shell и особенностей еe функционирования в Нигерии. Сиротински заключает, что корпоративное гражданство представляет собой эффективный инструмент взаимодействия бизнеса и общества, но в настоящий момент не может заменить государственное регулирование и государственные институты. В целом же автор не приходит к четким выводам, а расширяет и конкретизирует нерешенные проблемы в области корпоративного гражданства, мультинациональных компаний, законодательства и государственного регулирования.

\section{3. Взаимодействие корпораций с заинтересованными лицами}

Корпоративная социальная ответственность учитывает интересы многих стейкхолдеров. Стейкхолдер - это человек или организация, имеющая влияние на компанию или подверженная ее влиянию. Примером могут служить работники компании, покупатели, правительство, общественные организации. У каждого стейкхолдера свои интересы и потребности. В идеале компания должна стремиться к балансу интересов и потребностей различных заинтересованных сторон. Различают внутренних и внешних стейкхолдеров. К первым относятся работники, акционеры, менеджеры компании, ко вторым - профсоюзы, общественные организации, поставщики, кредиторы и пр.

Многие крупные компании испытывают серьезное давление со стороны своих стейкхолдеров. Требуемые стейкхолдерами действия в области КСО могут включать множество вещей: от использования более экологически чистых материалов в продукции до удовлетворения интересов конкретных некоммерческих организаций. В своей работе Паул [Paul, 2006] развивает точку зрения, что экономически рациональные компании должны позволять вовлекать себя в подобную деятельность только тогда, когда выгоды превышают издержки. В исследованиях Барон [Baron, 2001], Багноли и Уотс [Bagnoli, Watts, 2003] выражается мнение, что компании вовлекаются в «максимизирующую прибыль» деятельность, связанную с КСО, основываясь на ожидаемых выгодах от данных действий. Примером может служить улучшение репутации, возможность добавить премию к цене своей продукции, повышение возможности найма и удержания высококвалифицированных работников.

Целый ряд исследований направлен на поиск ответа на вопрос: позволяют ли социальная ответственность фирмам достичь более высокого уровня эффективности? Среди них можно отметить Гриффин и Махон [Griffin and Mahon, 1997], Доуэл, Харт, Йенг [Dowell, Hart, Yeung, 2000], Маквильямс, Сигел [McWilliams, Siegel, 2000] и Орлицки, Шмидт и Райнс [Orlitzky, Schmidt and Rynes, 2003]. Ответ на вопрос ищется с точки зрения изменения рыночной цены на акции или бухгалтерских показателей прибыльности. Подобные исследования при проведении эмпирического анализа рассматривают именно фирмы, а не все общество или конкретный сектор как единицу наблюдения. С одной стороны, это удобно, так как по фирмам доступно множество постоянно обновляемой информации; с другой стороны, целый ряд эффектов, влияющих на благосостояние, выпускается из виду.

Очень много работ посвящено влиянию инициатив в области корпоративной социальной ответственности на потребителей. Такие работы часто находятся на пересечении финансовой области знаний с маркетингом. Ранние исследования исходили из однозначной предпосылки, что потребители будут более лояльны к фирмам, вносящим вклад в развитие различных социальных программ. Однако 
сейчас исследователи сходятся на том, что потребители оценят далеко не каждое действие компании в области КСО [Barone et al., 2000; Brown and Dacin, 1997; Creyer and Ross, 1997; Ellen et al., 2000]. Исследования показывают, что потребители своим поведением могут даже наказать компании, если найдут их социальные инициативы неискренними [Sen, Bhattacharya, 2001; Simmons, BeckerOlsen, 2004].

В своем исследовании [Becker-Olsen, Cudmore, Hill, 2006] Беккер-Ольсен, Кюдмор и Хилл показывают, что реакция потребителей зависит от их восприятия действий в области КСО, а не от самих действий. Они оценивают важность связи корпоративной миссии и социальной инициативы, мотива корпорации (ориентированность на получение прибыль или нет), а также времени объявления (реактивное или проактивное) во влиянии на ответное поведение потребителей. Авторы приходят к выводу, что к положительному эффекту приводят только те социальные инициативы, которые хорошо согласуются с миссией компании и воспринимаются проактивными, а не реактивными. Для получения выводов они использовали статистическую обработку результатов определенного ряда проведенных опросов.

Концепция социальной ответственности вносит определенный вклад в дискуссии о целях существования корпораций. Существуют ли они только для создания прибыли и достижения интересов своих акционеров или также имеют определенную ответственность в социальной области перед другими стейкхолдерами?

Признанный специалист в области теории стейкхолдеров и бизнес-этики Эдвард Фриман, в своей работе с соавторами [Freeman, Velamuri, Moriarty, 2006] указывает на то, что существуют четыре уровня подхода к стейкхолдерам. Первый - это продвижение основных ценностей. Здесь закладывается понимание того, как добиться улучшения положения стейкхолдеров. Последний уровень - этическое лидерство. Исследования показывают, что существует довольно сильная связь между этическими ценностями и устойчивым развитием фирмы. Проактивное этическое лидерство возможно, только если компания имеет четкое видение интересов, приоритетов и забот своих стейкхолдеров.

Фриман выделяет 10 принципов, развивающих мышление в области ответственности компании перед своими стейкхолдерами.

1. Постоянное отслеживание интересов стейкхолдеров. Основная идея взаимодействия со стейкхолдерами заключается в понимании того, что процесс создания стоимости является совместным действием. Компании должны приносить доходность своим акционерам, выполнять обязательства перед кредиторами, банками. Менеджеры должны пытаться балансировать интересы стейкхолдеров.

Например, онлайн-аукцион еВау постоянно обновляет свой интерфейс и бизнес-процессы, чтобы отвечать ожиданиям и запросам множества групп стейкхолдеров. Способность компании постоянно удовлетворять потребности большого числа покупателей и продавцов принесла огромную выгоду акционерам, рыночная цена акций с 1999-го по 2006 год выросла на 400\%.

2. Признание того, что стейкхолдеры это реальные, сложные люди с именами, лищами и иенностями. Работники более мотивированы работать в компании, ценности и миссию которой они разделяют. Фирма со своей стороны должна понимать их ценности.

3. Поиск решений вопросов, которые удовлетворят сразу несколько групп стейкхолдеров одновременно.

4. Вовлечение в интенсивное взаимодействие со стейкхолдерами, и не только с дружелюбными; необходимо обязательно вести диалог различными методами с клиентами, поставщиками, служащими и акционерами, а также не 
забывать о различных обществах, средствах массовой информации, критиках и прочих второстепенных стейкхолдерах.

5. Философия волюнтаризма - стремление самим управлять взаимоотношениями со стейкхолдерам, а не оставлять это правительству. Вызовом для менеджеров может оказаться необходимость изменить мышление и добровольно сделать управленческие процессы более ответственными для стейкхолдеров. Если в этот процесс вмешивается государство, значит, менеджмент не смог выполнить свою задачу.

6. Обобщение маркетингового подхода: необходимо наращивать усилия компании, направленные на понимание потребностей стейкхолдеров, используя маркетинговые приемы сегментации стейкхолдеров для развития лучшего понимания их индивидуальных потребностей и использования маркетинговых приемов для понимания многосторонней природы большинства групп стейкхолдеров.

7. Никогда не ставить интересы одного стейкхолдера превыше интересов другого на продолжительном отрезке времени; концепции «служить покупателям» и «служить работникам» можно обобщить в философию «служить своим стейкхолдерам».

8. Проведение переговоров с первичными и вторичными стейкхолдерами. Если группа или индивид могут повлиять на компанию, то необходимо некоторое взаимодействие и стратегическое мышление. В сравнительно открытом и свободном обществе последствия отсутствия взаимодействия с широким кругом стейкхолдеров могут вылиться в дополнительные ограничения и требования со стороны государства.

9. Постоянной мониторинг и изменение процессов, чтобы лучше служить своим стейкхолдерам. Каким бы ни было взаимодействие со стейкхолдерами, его всегда можно улучшить.

10. Руководствоваться щеелью выполнять обещания, данные стейкхолдерам. Стремиться к достижению своих и их желаний.

Большинство организаций должно генерировать прибыли, иначе им не удастся достигнуть своей цели. И они не могут генерировать прибыли без интенсивного взаимодействия со стейкхолдерами.

Возросшая готовность бизнеса вовлекаться в диалог и дальнейшее партнерство с различными гражданскими группами означает рост числа ключевых инициатив, которые возникают благодаря совместному мышлению и направлены на решение вопросов корпоративного гражданства. Корпоративное гражданство является в настоящий момент предметом многих обсуждений, исследователи и практики ищут общее понимание данной концепции и последствия вовлечения для бизнеса, гражданского общества и правительств по всему миру. Какова должна быть связь между бизнесом и обществом? Несмотря на сложности, связанные с тем, что концепция до конца еще не успела устояться, можно наблюдать повышенный интерес бизнеса к диалогу и партнерству с рядом гражданских общественных организаций.

В своей работе Андриоф и Макинтош [Andriof, McIntosh, 2001] полагают, что корпоративное гражданство включает в себя не только юридически определенные права и обязанности, но и некий политический элемент, несущий дополнительные обязанности. Последние выходят за границы одной фирмы и существуют в трех измерениях: экономическом, социальном и экологическом. Таким образом, корпоративное гражданство накладывается на уже устоявшееся понятие корпоративной социальной ответственности, является более широким и означает, что корпорации должны расширить свой горизонт интересов за традиционные рамки. 
Среди исследователей, которые внесли большой вклад в развитие понятия корпоративного гражданства, можно отметить Вуд и Логсдон [Wood, Logsdon, 2002]. Они выделяют следующие возможности вовлечения компании в область гражданской ответственности:

- социальные права: приватизация общественных сервисов, оказание помощи бездомным людям, улучшение инфраструктуры и пр.;

- гражданские права;

- политические права: лоббирование, финансирование партий, политическая деятельность.

Анализ зарубежных академических работ показывает, что в последнее время теория стейкхолдеров развивалась в сторону важности вовлечения стейкхолдеров в долгосрочное создание стоимости компании. Это процесс, в котором важно долгосрочное сотрудничество, а не получение сиюминутной прибыли. Естественно, это не подразумевает, что прибыль не играет никакой роли. Аргументация строится на том, что для того чтобы выжить и получать устойчивую прибыль, компании должны максимально привлекать в свою деятельность различных стейкхолдеров, от которых они зависят.

В связи с этим компании начали выпускать отчеты, в которых как раз и отражается взаимодействие со стейкхолдерами. Впервые компании стали публиковать социальную отчетность в Европе в 90-х годах прошлого века. В последнее время все большее распространение получают стандартизированные формы отчетности. Среди наиболее признанных следует отметить Стандарт AА1000, разработанный Институтом социальной и этической отчетности в Лондоне, а также Руководство GRI, разработанное Глобальной инициативой по отчетности в Амстердаме. Основной упор в данных отчетах делается на взаимодействие со стейкхолдерами.

Например, в основе Стандарта АА1000, принятого в 1999 году, лежат следующие три принципа:

1. принцип материальности - отчет включает информацию об успешности устойчивого развития организации, необходимую стейкхолдерам для принятия информированных решений и действий;

2. принцип завершенности - оценка степени, в которой организация идентифицирует и понимает материальные аспекты устойчивого развития;

3. принцип ответственности - оценка ответных действий организации на запросы стейкхолдеров.

Развитие этого стандарта стимулировалось и признанием того, что организациям необходима поддержка в развитии социальных и этических инициатив, а также в выстраивании прогрессивных взаимоотношений с расширенной группой стейкхолдеров. Стандарт ценится за то, что позволяет достаточно точно указать на недостатки и пробелы в социальной стратегии компании, дать оценку общему управлению компанией.

В исследования проблематики корпоративной ответственности акцент смещается с самих стейкхолдеров на формы взаимодействия с ними, к которым прибегают компании. Исследование Майгнан и др. [Maignan et al., 1999] показывает наличие потенциальных выгод от внутренней и внешней КСОактивности. Тем не менее, если КСО в целом воспринимается положительно [Brown \& Dacin, 1997], то сообщения о КСО, как правило, рассматриваются довольно критично. Исследования показывают, что чем больше компания говорит о своих этических и социальных амбициях, тем более вероятно, что она столкнется с критическим отношением стейкхолдеров.

Ожидания стейкхолдеров постоянно меняются, и их нужно тщательно и регулярно отслеживать. При этом выстроенные соответствующим образом 
взаимоотношения со стейкхолдерами могут быть рассмотрены как источник конкурентных преимуществ.

Основываясь на работе Груниг и Хант [Grunig \& Hunt, 1984], исследователи Морсинганд и Шульц [Morsingand, Schultz, 2006] рассматривают три модели отношений со стейкхолдерами: стратегия информирования (information strategy), стратегия реагирования (response strategy) и стратегия вовлечения (involvement strategy).

1. Стратегия информирования. При данной стратегии связь является односторонней: от компании к стейкхолдерам. Основной целью является распространение объективной информации о деятельности организации. Такая информационная модель предполагает, что стейкхолдеры являются достаточно влиятельными, они могут как поддержать организацию (лояльностью, потребительскими привычками), так и причинить ей вред (через демонстрации, забастовки, бойкоты). Поэтому компания и должна информировать о своих хороших намерениях, решениях и действиях для того, чтобы обеспечить себе поддержку стейкхолдеров. Таким образом, одна из основных задач данной стратегии заключается в эффективной передаче сообщений о решениях компании в области КСО.

2. Стратегия реагирования. Данная стратегия основана на двусторонней асимметричной коммуникационной модели, в отличие от двусторонней симметричной модели в случае стратегии вовлечения. В обеих моделях информация движется как к публике, так и от нее. Основное различие между моделями заключается в том, что асимметричная модель предполагает отсутствие равновесия в отношениях с общественностью, так как компания не меняется в результате подобного взаимодействия. Вместо этого она старается изменить общественное отношение и поведение. Отдел по корпоративным коммуникациям в этом случае будет проводить опросы, рыночные исследования для наблюдения за тем, где компания улучшила или могла бы улучшить свои действия в области КСО. Взаимодействие воспринимается в форме обратной связи в виде результатов исследований о том, что публика примет. Стейкхолдеры рассматриваются влиятельными, но лишь пассивно реагирующими на инициативы корпорации. Получается, что компания в своих попытках понять потребности стейкхолдеров рискует услышать лишь эхо своего послания, так как компания задает вопросы в рамках, подразумевающих заранее определенные ответы, которые она хочет услышать.

3. Стратегия вовлечения. Данная стратегия подразумевает диалог со стейкхолдерами. Как организация, так и стейкхолдеры имеют шанс убедить своего оппонента измениться. В идеале измениться к лучшему должны обе стороны - в результате вовлечения в симметричную модель коммуникации. Компании должны стремиться не только оказывать влияние на стейкхолдеров, но и подвергаться такому влиянию с их стороны. Например, вместо того чтобы сразу действовать в рамках определенной социальной инициативы, при данной стратегии компании следует провести переговоры со своими стейкхолдарами по поводу их отношения к данной инициативе и принять определенные изменения в данной инициативе, если они будут признаны необходимыми. Стратегия вовлечения согласуется с двумя другими рассмотренными выше в вопросе влиятельности стейкхолдеров, однако отличается тем, что находит информирование и проведение опросов необходимым, но не достаточным, предполагает систематический взаимовыгодный диалог между компанией и ее стейкхолдерами. 
Несмотря на то что здесь представлены три стратегии коммуникации при КСО, на данный момент нет эмпирических подтверждений, что двусторонняя стратегия на сегодняшний день является широко практикуемой.

В своем исследовании авторы провели анализ мнений стейкхолдеров по поводу коммуникаций компаний в области КСО. Исследование построено на базе опроса свыше 10000 респондентов-стейкхолдеров в трех странах: Дании, Швеции и Норвегии. Авторы приходят к выводу, что все три стратегии жизнеспособны и полезны по-своему, тем не менее компании должны стремиться постоянно совершенствовать способы коммуникации со стейкхолдерами для достижения положительно эффекта и максимизации своей стоимости.

Правильно выстроенные отношения со стейкхолдерами позволяют компании значительно снизить риски.

В работе Хил и Гаррет [Heal, Garret, 2004] на ряде примеров раскрываются некоторые уязвимые стороны компаний. Например, такие компании, как McDonalds, Mitsubishi, Monsanto, Nestle, Nike, Shell, получили серьезный удар по своей репутации и уровню продаж в результате кампаний по поддержке групп стейкхолдеров. Очевидно, что Интернет теперь легко позволяет активистам со всего мира устраивать координированные бойкоты против корпораций с прямым воздействием на их продажи, хотя пока и в небольшом объеме относительно их объема рынка.

Кроме прямого воздействия на продажи существуют и другие последствия таких акций, возможно, более ощутимые для акционеров:

- Сокращение доли рынка компании на определенных рынках (например, Monsanto и ее генетически модифицированные продукты в Европе).

- Потеря статуса желаемого поставщика или работодателя (примером может служить опыт Shell).

- Снижение стоимости бренда.

Такие события связаны с прямыми издержками компаний по реинвестированию в репутацию, например:

- найм дополнительного персонала для мониторинга внутренних процессов, вызывающих вопросы;

- дополнительные затраты времени топ-менеджмента для разрешения конфликтных ситуаций;

- расходы на рекламу;

- расходы на дополнительные компенсационные выплаты;

- издержки на восстановление физически поврежденной собственности (ярким примером является McDonalds после антиглобалистских атак).

\section{4. Социально ответственные инвестиции}

Рост социально ответственных инвестиций позволяет предположить некоторую связь между отношением фирмы к социальной ответственности и ее финансовыми результатами на рынке. Сторонники КСО также утверждают, что социальная ответственность способна увеличить прибыли в долгосрочном периоде.

Работа Довел, Харт и Юнг [Dowell Hart, Yeung, 2000] является одной из самых ранних в области исследования связи между SRI и эффективностью деятельности компании. Авторы обнаружили положительную корреляцию между Q Тобина и экологической деятельностью компаний. В выборку вошли производственные компании США из индекса $\mathrm{S} \& \mathrm{P} 500$, ведущие свою деятельность в США и странах со средними доходами. Фирмы были разделены на три категории. В первую попали компании, которые работают по экологическим 
стандартам США по всему миру. Во вторую - работающие по единым, более высоким, чем в США, стандартам. В третью категорию вошли фирмы, которые применяют более низкие стандарты там, где это возможно. Ясно, что уровень применяемых экологических стандартов выше у 2-й группы, чем у 1-й, и у 1-й группы - чем у 3-й. В своем исследовании Довел, Харт и Юнг обнаруживают корреляцию номера группы с Q Тобина. Несмотря на множество слабых мест и ограничений в указанной работе, она задала тон дальнейшим исследованиям.

Кинг и Леннокс [ing and Lennox] провели похожее исследование, использовав другую, более объемную выборку фирм, и пришли к выводу, что некая связь между меньшим уровнем загрязнения (количеством эмиссий) и более высокими финансовыми результатами (Q Тобина) действительно существует. Однако установить направление влияния им также не удалось.

Сегодня существует целый ряд индексов, в которые включены бумаги социально ответственных компаний. Компания KLD составляет индекс «DS 400 Index», который не включает компании, получающие доходы от производства или продажи алкогольных, табачных изделий, от предоставления игровых продуктов и сервисов и получающие более $2 \%$ выручки от систем вооружения. KLD также оценивает компании по их достижениям в области экологии, диверсификации и отношений с работниками. KLD старается исключать только те компании, чей профайл в целом является негативным.

Можно отметить также индекс The Dow Jones Sustainability Index (DJSI), основанный на исследованиях SAM Group: он не исключает автоматически табачные и алкогольные компании. Вместо этого используется метод «лучшего в своем классе» для включения лучших компаний, работающих в каждой отрасли индустрии. DJSI включает лидеров по корпоративной устойчивости.

K сожалению, сравнивать динамику этих индексов с такими распространенными индексами, как S\&P 500, напрямую не имеет смысла, так как существует множество моментов, не позволяющих делать конкретные выводы. Более подробный анализ можно найти в работе Статман [Statman, 2007]. Несколько другой аспект вопроса в своей работе рассматривают Гецжи, Стамбо и Левин [Geczy, Stambaugh and Levin, 2003]: они исследуют эффективность работы SRI-фондов. Указанные авторы присоединяются к мнению, что данные фонды, действие которых ограничено этическими соображениями, должны всегда уступать по эффективности фондам, работающим без таких ограничений. Данный аргумент ни в коем случае не связан с финансовыми результатами компаний с активными программами в области КСО. Идея заключается в том, что сужая набор, из которого можно выбирать акции, менеджер фонда никоим образом не может улучшить деятельность фонда - он может его только ухудшить, что полностью согласуется с САРМ.

Однако рассуждения, в основе которых лежит подобная логика, не учитывают, что стохастические свойства цен акций неизвестны и программы КСО могут добавить информацию, которая была бы недоступна инвесторам из других источников. Получается, что SRI-фонды все-таки могут обойти прочие по доходности. К сожалению, данные о деятельности фондов, которые могли бы разрешить вопрос, двусмысленны. Некоторые SRI-фонды постоянно обыгрывали рынок, но это может быть лишь отражением навыков менеджеров, а не инвестиционной философии. Исследование Байер, Кудийк, Оттен [Bauer, Koedijk, Otten] показывает, что SRI-фонды в Великобритании несколько эффективнее своих не-SRI-конкурентов. В США ситуация схожая, но до 1995 года картина была обратной.

Интересный подход использовало агентство Innovest, предоставляющее рейтинги социальной ответственности, при оценке портфелей SRI. Рассматривался 
определенный стандартный инвестиционный портфель и ставился вопрос: что будет, если акции в данном портфеле заменить на похожие (тот же сектор, те же финансовые характеристики), но с более высоким рейтингом КСО? Далее агентство Innovest отслеживает оба портфеля и находит, что практически во всех случаях модифицированный портфель лучше первоначального.

Достаточно подробное рассмотрение связи между корпоративной социальной ответственностью и финансовыми показателями, в которых заинтересованы инвесторы, можно найти в работе Хила [Heal, 2004]. Он определяет роль политик в рамках корпоративной социальной ответственности как предвидение и минимизацию конфликтов между корпорациями и обществом. Список выгод от программ в области корпоративной социальной ответственности, предложенный этим автором, включает:

1. Снижение риска.

2. Снижение уровня отходов.

3. Улучшение отношений с регулирующими органами.

4. Создание и поддержание бренда.

5. Улучшение человеческих отношений и производительности работников.

6. Снижение стоимости капитала.

Одной из основных проблем введения в практику компаний принципов КСО в настоящий момент является краткосрочность ориентирования стратегий развития компаний, их зависимость от движений на фондовом рынке. О губительных последствиях ориентированности на краткосрочных инвесторов для долгосрочного развития компании не раз говорил Уоррен Баффетт [Baffett, 2007], однако проблема до сих пор существует и во многом поддерживается современной теорией финансов. В данной ситуации развитие корпоративной социальной ответственности, бесспорно, затруднено, так как, преследуя краткосрочные высокие финансовые результаты, компаниям, как правило, приходится пренебрегать не только долгосрочным развитием, но и перекладывать на потребителей внешние эффекты более затратного и экологически вредного производства. Вариант, предлагаемый Митчеллом [Mitchell, 2007] и находящий отголоски и в собрании эссе Баффетта [Baffett, 2007], заключается в том, что необходимо рассмотреть развитие КСО в терминах развития корпоративного управления. В свою очередь, это означает, что если в корпорации целью корпоративного управления будет долгосрочное развитие компании, то автоматически будут достигаться и цели КСО. Однако вопрос приверженности компании долгосрочным целям развития или же подчинения рыночному давлению, заставляющему думать о ее краткосрочной эффективности, наиболее остро стоит перед советом директоров. Таким образом, именно он может выступить в качестве движущей силы развития корпоративной социальной ответственности.

В работе Митчелл [Mitchell, 2007] представлен ряд способов снижения давления на совет директоров со стороны рынка и, как следствия, возможности ведения более социально ответственного бизнеса. Это в первую очередь изменение налоговых преимуществ для держателей акций с целью стимулирования долгосрочных инвестиций ${ }^{26}$. Другим способом увеличения долгосрочных инициатив совета директоров может стать его переизбрание каждые 5 лет, с тем чтобы за данный временной интервал у совета директоров была возможность претворить долгосрочный стратегический план развития компании в действительность. Во многом на деятельность совета директоров может повлиять и введение новых правил ведения учета, которые, например, будут рассматривать превышение заработной платы над среднеотраслевой как капитализируемую

\footnotetext{
${ }^{26}$ Данная мера, однако, требует определения долгосрочного периода для каждой отрасли. 
сумму, подлежащую амортизации на протяжении определенного периода. Иными словами, измененные правила учета способны стимулировать корпорации с бо́льшим вниманием относиться к персоналу и в целом к принципам КСО.

В то время как ряд исследований рассматривает роль советов директоров в установлении корпоративной социальной ответственности в компании, мало сказано о роли внедрения КСО для советов директоров. Обзор исследований позволил сделать вывод исключительно о росте репутации социально ответственных советов директоров и о появлении большей независимости у неисполнительных директоров. Однако, по утверждению Хопкинса [Hopkins, 2004], внедрение КСО также сопряжено с многочисленными совещаниями и прессконференциями, что существенно увеличивает ответственность совета директоров и затраты времени.

\section{5. Корпоративная социальная отчетность}

Термин «нефинансовая отчетность» не относится к ряду общепринятых определений. В различных работах можно встретить такие его синонимы, как «корпоративная социальная отчетность», «социально ответственная отчетность», «социальная отчетность», «социальная и экологическая отчетность».

Так, Ассоциация менеджеров [2004] использует термин «корпоративный социальный отчет», под которым подразумевает «публичный инструмент информирования акционеров, сотрудников, партнеров и всего общества о том, как и какими темпами компания реализует заложенные в своей миссии или стратегических планах развития цели экономической устойчивости, социального благополучия и экологической стабильности».

Распространение идей устойчивого развития компаний и необходимости следовать принципам корпоративной социальной ответственности привело к тому, что стандартная финансовая отчетность перестала быть достаточной. Таким образом необходимой стала расширенная отчетность, включающая целый ряд прочих показателей кроме традиционных. Одним из вариантов сочетания необходимых показателей в отчетности компании является подход Triple Bottom line (3BL, тройной критерий). Согласно этой концепции ${ }^{27}$, результативность вклада компании в развитие общества можно оценить по трем аспектам ее деятельности: экономическому, социальному и экологическому. Именно данные три раздела представлены в корпоративной социальной отчетности.

Экономический раздел корпоративной социальной отчетности покрывает не только финансовые показатели компании - он также нацелен на раскрытие вклада компании в развитие национальной экономики и на описание ее экономической стратегии развития. В этом разделе среди основных показателей можно встретить данные отчета о прибылях и убытках, размеры инвестиций в интеллектуальный капитал, внутренние и внешние социальные программы, результаты оценки удовлетворенности потребителей, сведения о качестве продукции. Целью составления социального раздела отчетности является сделать достоянием общественности вклад компании в охрану труда и здоровья персонала, описание социальных программ помощи населению, в которых приняла участие компания, доказательство соблюдения ею прав человека. Основные показатели данного раздела описывают существующие на предприятии правила управления персоналом, корпоративный кодекс фирмы, отношения компании с населением. Третий, экологический, аспект направлен на раскрытие информации о защите окружающей среды, применяемых компанией технологиях для поддержания

\footnotetext{
${ }^{27}$ Термин был введен Элкингтоном [Elkington, 1997].

Выпуск \#2, 2007 (C) Электронный журнал Корпоративные Финансы, 2007
} 
экологического баланса. В этом разделе представлены показатели потребления энергии, водных и прочих ресурсов, данные о выбросах различных категорий загрязняющих веществ.

Переход компании на предоставление отчетности в соответствии с тройным критерием увеличивает ее прозрачность, что, согласно теории корпоративных финансов, должно сказаться на снижении затрат на капитал. Именно изучению данного вопроса посвящена работа Бассена и Мейера [Bassen, Meyer, 2006]. В своем исследовании авторы использовали трехстадийный анализ: исследование аналитиков и инвесторов коммунальных предприятий (онлайн-анкетирование), ранжирование данных компаний в соответствии с авторской точкой зрения, основанной на тройном критерии, а также корреляционный и многостадийный линейный регрессионный анализ. Авторы выявили ярко выраженное влияние корпоративной социальной отчетности на снижение рисков компании. В силу того что риск является основным параметром, влияющим на затраты на капитал компании, авторы заключили, что компании с социально ответственным поведением в состоянии снизить затраты на капитал.

Когда компания придерживается принципов КСО в своей деятельности, возникает вопрос фиксирования результатов социальной, экологической и прочей активности в отчетности. Однако столь ли это необходимо? Не достаточно ли компании зафиксировать в финансовой отчетности сумму средств, затраченных в данном периоде на социальные и экологические проекты?

Вопрос необходимости для бизнеса ведения нефинансовой отчетности представляет собой достаточно серьезную проблему, ввиду того что проверить эмпирически влияние нефинансовой отчетности на деятельность компании крайне сложно. По этой причине большинство исследований данного раздела представляет собой дискуссионные работы либо работы, основанные на опросах.

Наиболее примитивная причинно-следственная связь, объясняющая привлекательность ведения нефинансовой отчетности для компаний, состоит в следующем. Ведение корпоративной социальной отчетности делает компанию более привлекательной для потребителей ввиду большей степени ее открытости, увеличивая тем самым и ее рентабельность. И несмотря на повышение затрат, необходимых на ведение нефинансовой отчетности, дополнительная прибыль превалирует ${ }^{28}$ [Hopkins, 2004].

Подробнее преимущества корпоративной социальной отчетности рассматриваются следующим образом. Нефинансовая отчетность представляет собой эффективный механизм предоставления и раскрытия информации о своей социальной и экологической деятельности, о степени интеграции принципов корпоративной социальной ответственности в деятельность компании. Предоставление подобной отчетности позволяет продемонстрировать, как заявленные компанией миссия, видение, стратегические цели реализуются компанией посредством социально ответственной деятельности, результаты которой и представлены в отчете. Так, согласно Беббингтон и Грей [Bebbington, Gray, 2001], социальная и экологическая отчетность позволяют показать, как связана компания с такими понятиями, как устойчивое развитие, и тем самым представляет собой не только «ворота из организации, но и ворота в нее».

Однако ключевым преимуществом отчетности, по мнению Ассоциации менеджеров, является ее доступность не только менеджменту, но и всем заинтересованным лицам:

\footnotetext{
${ }^{28}$ Следует сразу отметить, что часть авторов не разделяют компании на соблюдающие КСО, и те, которые не только поддерживают КСО, но и составляют отчетность, а имплицитно предполагают, что отчетность при следовании КСО составляется (например, Басен, Майер [Bassen, Meyer, 2006]). Чаще всего приходится ориентироваться на контекст исследования.
} 
- акционерам,

- персоналу,

- потребителям,

- деловым партнерам и поставщикам, контрагентам,

- сообществу (особенно государственным органам).

Доступность, таким образом, способствует развитию отношений между менеджментом компании и каждой из названных групп стейкхолдеров. Бесспорно, корпоративная социальная отчетность улучшает имидж, репутацию, узнаваемость бренда компании для всех групп. В силу того что репутация складывается из таких нематериальных активов, как доверие, надежность, качество, прозрачность, отношения с клиентами и материальными активами в виде инвестиций в человеческий капитал и окружающую среду, несоблюдение КСО может легко и существенно оказывать влияние на стоимость компании [Hopkins, 2004]. Однако это не единственное преимущество введения корпоративной социальной ответственности. Так, регулярное предоставление нефинансовой отчетности повышает доверие к компании со стороны акционеров. Для персонала информация о достижениях компании в области КСО, которую он может почерпнуть из нефинансовой отчетности, увеличивает мотивацию. Более того, развитие корпоративной этики на всех уровнях персонала приводит к улучшению рабочей атмосферы, снижению разногласий в коллективе и, как следствие, к росту производительности. Доступность информации потенциальному новому персоналу свою очередь не только способствует привлечению в компанию высококвалифицированных кадров, но и снижает издержки кадровой службы.

Что касается потребителей, то доступность корпоративной социальной отчетности не только улучшает имидж компании в глазах существующих и потенциальных потребителей. На самом деле отчетность можно рассматривать как рекламный продукт, который стимулирует продажи и одновременно укрепляет репутацию компании. Действие нефинансовой отчетности, однако, гораздо сильнее стандартной рекламной кампании, так как нефинансовая отчетность направлена на гораздо более обширный, чем круг покупателей, круг стейкхолдеров [Ассоциация менеджеров, 2004].

Ознакомление государственных органов с нефинансовой отчетностью увеличивает уверенность в компании, приводит к меньшему количеству судебных тяжб и более выгодным условиям функционирования [Hopkins, 2004].

Естественно, что ведение нефинансовой отчетности способствует и развитию отношений едва ли не с самой важной группой стейкхолдеров инвесторами. Доступность информации не только о финансовой, но и об экономической и социальной деятельности компании позволяет инвесторам провести тщательный анализ рисков и увеличивает вероятность инвестирования в компанию и ее проекты.

При всех положительных последствиях ведения нефинансовой отчетности существуют и причины, тормозящие ее воплощение в жизнь. Систематизации отрицательных последствий корпоративной социальной ответственности посвящена часть работы Хопкинса [Hopkins, 2004]. В первую очередь это финансовые затраты, необходимые на составление отчетности. Инвестиции в инновационные методы производства, в меньшей степени причиняющие вред экологии, также существенны. И естественно, необходимы средства для публикации корпоративной социальной отчетности в различных средствах массовой информации, так как созданная, но не доведенная до стейкхолдеров отчетность не принесет выгод. Существенны и временные затраты на составление нефинансовой отчетности. Данные затраты носят постоянный характер, так как отчетность имеет значение только в условиях регулярного составления. 
Однако для компании, только принявшей решение вести нефинансовую отчетность, проблемы гораздо масштабнее, так как необходимо принять решение о ведении отчетности при помощи стандартов или основываясь на каких-либо собственных нормативах, исходящих из концепции КСО, разработать систему ответственных за составления отчетности подразделений.

С оборотной стороной введения нефинансовой отчетности сталкивается и персонал компании, которому довольно часто приходится посещать множество семинаров по корпоративной этике, активизировать, иногда излишне, внутрикорпоративное общение. По мнению Хопкинса, последствиями этого могут стать краткосрочное повышение цен на сырье и соответственно стоимость продукции, а также увеличение издержек на приспособление к новым законодательным изменениям.

Однако одним из ключевых недостатков введения корпоративной социальной ответственности являются уже упомянутые проблемы анализа эффективности публикации отчетности. Более того, есть и такой класс стейкхолдеров, который рассматривает нефинансовую отчетность исключительно как негативную сторону рекламной кампании корпорации. С этой точки зрения отчетность начинает играть негативную роль: существенные финансовые средства компаний идут на рекламу вместо того, чтобы быть потраченными на социальные мероприятия либо реинвестирование.

Практически все эмпирические исследования, посвященные корпоративной социальной ответственности, проводятся с использованием данных крупных компаний США, что неслучайно. Приверженность к данным США связана с наиболее давней историей корпоративной социальной отчетности в США и других развитых рынков капитала. Исследования растущих рынков капитала встречаются крайне редко: даже если в стране появилась практика составления нефинансовой отчетности, имеющихся данных недостаточно для проведения исследований. Так, работа Арарата, Гоценоглу [Ararat, Gocenoglu, 2005], анализирующая движущие силы КСО в Турции, вынуждена базироваться на статистическом анализе отчетностей 30 компаний. Амаеши [Amaeshi, 2006], акцентируя внимание на финансовых институтах и корпоративной социальной ответственности в развивающихся странах, рассматривает данные исключительно Нигерии. Одно из редких исследований, оперирующих с данными 20 стран, в том числе и государств с растущими рынками капитала (например, Турции, России, Катара) Браммер, Уилльямс [Brammer, Williams, 2006] — анализирует влияние религии на отношение к корпоративной социальной ответственности.

Не менее понятно и повсеместное распространение исследований, проводимых с использованием данных крупных компаний (как правило, мультинациональных). Ввиду того что социально ответственная деятельность любой компании сопряжена с высокими затратами, доступна она в настоящее время исключительно крупным компаниям. Менее крупным компаниям, даже в случае приверженности принципам КСО, чаще всего не под силу публикация и популяризация нефинансовой отчетности. Источником данных для преобладающего большинства исследований служит именно нефинансовая отчетность либо включение компании в один из индексов социально ответственного поведения (причем чаще всего в эти выборки попадают именно крупные компании). Явным становится и наиболее распространенный в исследованиях результат, согласно которому размер компании не коррелирует с КСО: компании в выборке слабо отличаются по своей величине, что приводит к отсутствию корреляции (например, Бассен [Bassen, Meyer, 2006]). 


\section{Список литературы}

1. Баффетт У. Эссе об инвестициях, корпоративных финансах и управлении компаниями. М.: Альпина Бизнес Букс, 2007 г.

2. Иванова Е.А., Акопян А.Р., Литовченко С.Е. Корпоративный социальный отчет: как правильно рассказать о вкладе вашей компании в развитие общества. Практическое руководство. М.: Ассоциация менеджеров, 2004 г.

3. Корпоративная социальная ответственность: общественные ожидания. Потребители, менеджеры, лидеры общественного мнения и эксперты оценивают социальную роль бизнеса в России. М.: Ассоциация менеджеров, 2003 г.

4. Черныш М.Ф., Иванова Е.А. Корпоративная социальная ответственность: общественные ожидания. Потребители, менеджеры, СМИ и чиновники оценивают социальную роль бизнеса в России. М.: Ассоциация менеджеров, 2004 г.

5. Amaeshi Kenneth M.. Financial Exclusion, Financial Institutions and Corporate Social Responsibility: A developing country perspective //Working paper. 2006.

6. Andriof, J, \& McIntosh, M (Eds.) Perspectives on corporate citizenship // Sheffield, Greenleaf, 2001.

7. Ararat Melsa, Göcenoğlu Ceyhun. Drivers for Sustainable Corporate Responsibility, Case of Turkey// Working paper. 2005.

8. Bagnoli, M. and S. Watts. Selling to Socially Responsible Consumers: Competition and the Private Provision of Public Goods // Journal of Economics and Management Strategy, 2003, 12:419-445.

9. Baron, D. Private politics, corporate social responsibility and integrated strategy // Journal of Economics and Management Strategy.2001, 10:7-45.

10. Barone Michael J, Miyazaki Anthony D, Taylor Kimberly A. The influence of cause-related marketing on consumer choice: does one good turn deserve another? // J Acad Mark Sci, 2000, 28, pp. 248-262.

11. Bassen Prof. Dr. Alexander, Meyer Katrin, Schlange Joachim. The Influence of Corporate Responsibility on the Cost of Capital// Working paper. 2006.

12. Bauer R., K. Koedijk and R. Otten, (2005), International Evidence on Ethical Mutual Fund Performance and Investment Style, Journal of Banking and Finance, Vol. 29, pp. 1751-1767.

13. Bebbington Jan, Gray Rob. Accounts of Sustainable Development: the Construction of Meaning within Environmental Reporting//Working paper. 2001.

14. Becchetti Leonardo, Giacomo Stefania Di, Pinnacchio Damiano. Corporate Social Responsibility and Corporate Performance: Evidence from a panel of US Listed Companies//CEIS Tor Vergata - Research Paper Series. Vol. 26. № 78. 2005.

15. Becker-Olsen Karen L., B. Andrew Cudmore, Ronald Paul Hill The impact of perceived corporate social responsibility on consumer behavior // Journal of Business Research, 2006, 59, pp. 46-53/

16. Beckmann Markus, Pies Ingo. Sustainability by Corporate Citizenship- The Moral Dimension of Sustainability// Working paper. 2007.

17. Bertinelli Luisito, Strobl Eric, Zou Benteng. Sustainable Economic Development and the Environment: Theory and Evidence// Working paper. 2006.

18. Brammer Stephen, Brooks Chris, Pavelin Stephen. The Stock Performance of America's 100 Best Corporate Citizens//Working paper. 2005.

19. Brammer Stephen, Williams Geoffrey, Zinkin John. Religion and Attitudes to Corporate Social Responsibility in a Large Cross-Country Sample// Working paper. 2006. 
20. Brown Tom J, Dacin Peter A. The company and the product: corporate associations and consumer product responses. // J Mark, 1997, 61(1):68-85.

21. Caratti Pietro, Cascio Gabriella Lo. Sustainable Development Policies in Europe// Working paper. 2006.

22. Cerin Pontus, Karlson Lennart. Business incentives for sustainability: a property rights approach// Ecological Economics. 40. 2002, pp. 13-22.

23. Creyer Elizabeth, Ross William T. The influence of firm behavior on purchase intention: do consumers really care about business ethics? // J Consum Mark, 1997, 14(6), pp. 421-428.

24. Dowell, Hart, S. and Yeung, B. Do corporate global environmental standards create or destroy market value? // Management Science, 2000, 46, 8, 10591074.

25. Elkington J. Cannibals with Forks: The Triple Bottom Line of $21^{\text {st }}$ Century Business// Capstone Publishing. 1997.

26. Ellen Pam Schoder, Mohr Lois A, Web Deborah J. Charitable programs and the retailer: do they mix? // J Retail, 2000;76 (3):393-406.

27. Finch Nigel. The Motivations for Adopting Sustainability Disclosure// Working paper. 2005.

28. Freeman R. Edward, S. Ramakrishna Velamuri, Brian Moriarty Company Stakeholder Responsibility: A New Approach to CSR // Business Roundtable Institute for Corporate Ethics, 2006.

29. Friedman Milton. Capitalism and Freedom// University of Chicago Press. 1962.

30. Friedman Milton. The social responsibility of business is to increase its profits// New York Times. September 13. 1970.

31. Geczy Christopher C., Robert F. Stambaugh, David Levin Investing in Socially Responsible Mutual Funds // Working Paper, The Wharton School of the University of Pennsylvania, 2003.

32. Griffin, J.J. and J.F Mahon. The Corporate Social Performance and Corporate Financial Performance Debate: Twenty-five years of Incomparable Research. // Business and Society, 1997, 36 (1): 5-31.

33. Grunig, J.E. and Hunt, T. 1984. Managing Public Relations. Fort Worth, TX: Harcourt Brace Jovanovich College Publishers.

34. Heal Geoffrey, Paul Garret Corporate Social Responsibility // An Economic and Financial Framework, 2004.

35. Hopkins Michael. Corporate social responsibility: an issues paper// Working paper. 2004.

36. King and Lennox Does It Really Pay to Be Green? An Empirical Study of Firm Environmental and Financial Performance // Journal of Industrial Ecology, Volume 5. № 1 http://mitpress.mit.edu/JIE

37. Kumari Dr. Areti Krishna. Understandind Sustainable Development// Working paper. 2007

38. Logsdon J.M. and Wood D.J. (2002) Business citizenship: from domestic to global level of analysis. Business Ethics Quarterly 12: 2155-187.

39. Mackey Alison, Mackey Tyson B., Barney Jay B.. Corporate Social Responsibility and Firm Performance: Investor Preferences and Corporate Strategies// Working paper. 2005.

40. Maignan, I., Ferrell, O.C. and Hult, G.T.M. Corporate citizenship: cultural antecedents and business benefits // Journal of the Academy of Marketing Science, 1999, 27:4, 455-469.

41. McWilliams A., Siegel D. Corporate Social Responsibility: a Theory of the Firm Perspective// Academy of Management Review. 2001, issue 26, volume 1. pp. $117-127$. 
42. McWilliams, A. and D. Siegel Corporate Social Responsibility and Financial Performance: Correlation or Misspecification? // Strategic Management Journal, 2000, 21(5): 603-609.

43. Melé Domènec. Corporate Social Responsibility in Spain: an Overview//Working paper. 2004.

44. Mitchell Lawrence E.. The board as a path toward corporate social responsibility// Working paper. 2007.

45. Morsingand and Schultz Corporate social responsibility communication: stakeholder information, response and involvement strategies // Business Ethics: A European Review, 2006, Volume 15, № 4.

46. Orlitzky, M., Schmidt, F.L., and S.L Rynes Corporate Social and Financial Performance: A Meta-Analysis // Organization Studies, 2003, 24 (3): 403- 441.

47. Paul Catherine J., Morrison Corporate Social Responsibility and Economic Performance // Working paper, 2006.

48. Sen Sankar, Bhattacharya CB. Does doing good always lead to doing better? Consumer reactions to corporate social responsibility // J Mark Res, 2001; 38(2): 225-43.

49. Simmons Carolyn, Becker-Olsen Karen. When do Social Sponsorship Enhance or Dilute Equity: Fit, Message Source and the Persistence of Effect // Working Paper, 2004.

50. Sirotinsky Lelia Mooney. On Corporate Citizenship// Working paper. 2004.

51. Statman M. Socially Responsible Investments // Working paper, 2007.

52. Werther Jr. William B., Chandler David. Strategic corporate social responsibility as global brand insurance// Business Horizons. 2005. 48, pp. 317-324. 